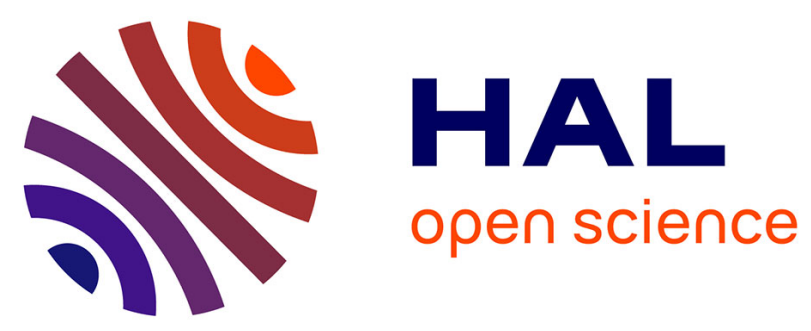

\title{
Combining cone calorimeter and PCFC to determine the mode of action of flame retardant additives
}

José-Marie Lopez-Cuesta, Rodolphe Sonnier, Laurent Ferry, Claire Longuet, Fouad Laoutid, Blandine Friedrich, Abdelghani Laachachi

\section{- To cite this version:}

José-Marie Lopez-Cuesta, Rodolphe Sonnier, Laurent Ferry, Claire Longuet, Fouad Laoutid, et al.. Combining cone calorimeter and PCFC to determine the mode of action of flame retardant additives. Polymers for Advanced Technologies, 2011, 22 (7), pp.1091. 10.1002/pat.1989 . hal-00649884

\section{HAL Id: hal-00649884 https://hal.science/hal-00649884}

Submitted on 9 Dec 2011

HAL is a multi-disciplinary open access archive for the deposit and dissemination of scientific research documents, whether they are published or not. The documents may come from teaching and research institutions in France or abroad, or from public or private research centers.
L'archive ouverte pluridisciplinaire $\mathbf{H A L}$, est destinée au dépôt et à la diffusion de documents scientifiques de niveau recherche, publiés ou non, émanant des établissements d'enseignement et de recherche français ou étrangers, des laboratoires publics ou privés. 


\section{Polymers for Advanced Technologies}

WILEY

\section{Combining cone calorimeter and PCFC to determine the mode of action of flame retardant additives}

\begin{tabular}{|c|c|}
\hline Journal: & Polymers for Advanced Technologies \\
\hline Manuscript ID: & PAT-10-641.R1 \\
\hline Wiley - Manuscript type: & Special Issue: Research Article \\
\hline $\begin{array}{r}\text { Date Submitted by the } \\
\text { Author: }\end{array}$ & 25-Feb-2011 \\
\hline Complete List of Authors: & $\begin{array}{l}\text { LOPEZ CUESTA, José-Marie; EMA, CMGD } \\
\text { sonnier, rodolphe; ema, CMGD } \\
\text { ferry, laurent; ema, CMGD } \\
\text { Longuet, Claire; ema, CMGD } \\
\text { laoutid, fouad; University of Mons, LPCM } \\
\text { friedrich, blandine; Centre de recherche Henry Tudor } \\
\text { laachachi, abdelghani; Centre de recherche Henry Tudor }\end{array}$ \\
\hline Keywords: & flame retardancy, cone calorimeter, pcfc, barrier effect \\
\hline
\end{tabular}




\title{
Combining cone calorimeter and PCFC to determine the mode of action of flame retardant additives
}

\author{
R. Sonnier ${ }^{1}$, L. Ferry ${ }^{1}$, C. Longuet ${ }^{1}$, F. Laoutid ${ }^{2}$, B. Friederich ${ }^{3}$, A. Laachachi ${ }^{3}$, J-M. Lopez- \\ Cuesta $^{1}$ \\ ${ }^{1}$ CMGD, Ecole des Mines d'Alès, 6, avenue de Clavières, 30319 Cedex Alès, France \\ ${ }^{2}$ Laboratory of Polymeric and Composite Materials (LPCM), University of Mons \& Materia Nova \\ Research Center, Place du Parc 20, 7000 Mons, Belgium \\ ${ }^{3}$ AMS - Centre de Recherche Public Henri Tudor - 66 Rue de Luxembourg, L-4002 Esch/Alzette, \\ Luxembourg
}

\section{Corresponding author: $\underline{\text { rodolphe.sonnier@mines-ales.fr }}$}

Keywords: flame retardancy, barrier effect, cone caloirmeter, microcalorimeter PCFC

\begin{abstract}
The flammability of various flame retarded formulations containing different hydrated mineral fillers and/or phosphorous compounds and/or carbon nanotubes has been investigated using both cone calorimeter and PCFC. A method was proposed to evaluate the barrier effect of the flame retardant additives. This method is based on the fact that PCFC is non sensitive to physical flame retardant effects while both chemical and physical phenomena have a great effect on cone calorimeter results. Therefore normalized pHRR values obtained with both techniques does not always show a good correlation. It was highlighted that the mismatch between both pHRR results was related to the formation of a protective layer during combustion. Protective layers have been evidenced independently by visual observations. Thus it is proposed that the magnitude of the deviation from a perfect correlation between cone calorimeter and PCFC pHRRs could be used to quantify the magnitude of barrier effect. While the results obtained from different fire tests are generally not correlated, such an approach based on the complementarity of different techniques appears more relevant despite of its empirical nature.
\end{abstract}

\section{Introduction}

It is well known that flame retardants (FR) additives reduce the flammability of polymers according to various modes of action [1]. Some of them act through chemical mechanisms, other through physical ones. Moreover, in some cases, their mechanisms of action concern mainly the condensed phase, in other cases, particularly when trapping of radicals or dilution of combustible gases are involved, their mechanisms operate in the gaseous phase. 
It is a challenging topic to evaluate the exact mode of action of a specific FR. Moreover, flame retardant additives are often components of more and more complex FR systems and often constituted by several components. Determining and optimizing possible synergies between different components of FR systems requires an accurate knowledge of modes of action of each additive.

Cone calorimetry, associating calorimetric analysis to mass loss measurements, are among the most effective and used techniques to investigate the mechanisms of action of fire retardants. To complement this technique, a pyrolysis combustion flow calorimeter (PCFC) can be employed, particularly when samples available are particularly thin or limited in weight. This technique was developed several years ago by Lyon [2]. A few milligrams sample is pyrolyzed under nitrogen flow according to a heating ramp (typically $1 \mathrm{~K} / \mathrm{s}$ ) up to $750^{\circ} \mathrm{C}$. The gases released during the pyrolysis are evacuated into an oven at $900^{\circ} \mathrm{C}$ in the presence of a $80 / 20 \mathrm{~N}_{2} / \mathrm{O}_{2}$ mixture. In these conditions, a total combustion of these gases takes place.

Similarly to cone calorimetry, PCFC calculates the heat release rate by measuring the consumption of oxygen, according to the Huggett's relation: $1 \mathrm{~kg}$ of consumed $\mathrm{O}_{2}$ corresponds to $13.1 \mathrm{MJ}$ of released energy. Moreover, a new parameter was introduced by Lyon: the Heat Release Capacity (or HRC), which corresponds to the pHRR (peak of heat release rate) measured in PCFC divided by the heating rate. This value is not dependent on the heating rate and is an intrinsic characteristic of a material. At $1 \mathrm{~K} / \mathrm{s}$, the HRC is equal to pHRR. In the case of a multistep decomposition, Lyon and al. have proposed to use the sumHRC which is the sum of the HRC of each peak after deconvolution.

On the whole, the reproducibility of the data in PCFC is very good, since generally less than $5 \%$ of deviation between two analyses for pHRR (and so on HRC) is obtained. The interest of PCFC has been addressed in several articles, particularly to predict cone calorimeter or LOI results. Lyon and Wagner partly achieved to connect some characteristics (Total Heat Released THR, HRC and weight of residue) measured in PCFC with the molecular structure of polymers according to the Van Krevelen approach [3, 4], based on the contribution of each chemical group to the heat released. Lyon and al. have studied the flammability of textile fibres with and without flame retardant additives using PCFC [5].

Morgan et al. [6] have performed a screening of epoxy-based formulations using PCFC. The best formulation based on these results was scaled up to obtain a fiberglass-reinforced composite which was tested with cone calorimeter. The authors noticed that the best choice based on PCFC results was not the same as that based on cone calorimeter results. In conclusion, the authors considered that "Using the microcalorimeter as a screening tool was partly incorrect. It was incorrect if only total HR and peak HRC were the only criteria for screening”. Schartel et al. [7] investigated flame retarded PCABS systems. They found some correlations between HRC and UL94 and especially LOI. 


\section{Experimental Part}

1- Description of the method

The method proposed is based on the assumption that some effects are efficient in cone calorimeter but not in PCFC. For example, barrier effect could be efficient on $10 * 10 * 0.4 \mathrm{~cm}^{3}$ samples (as in cone calorimeter) but not on 1 or $2 \mathrm{mg}$ samples (as in PCFC). Moreover, flame inhibition is not observed in PCFC because the combustion is complete. On the contrary, radicals trapping or endothermic effects which slow down the degradation of the material are efficient in both cases.

Hence, the decrease in pHRR in cone calorimeter test due to the incorporation of a flame retardant additive should be higher (or at least equal) than the decrease in pHRR (or HRC /sumHRC) in PCFC. The ratio between the HRC (or sumHRC) in PCFC of the flame retarded polymer and the HRC (or sumHRC) in PCFC of the non retarded polymer (at the same heating rate) is named R1 and the ratio between the pHRR in cone calorimeter of the flame retarded polymer and the pHRR in cone calorimeter of the non retarded polymer (at the same irradiance) is named R2. It is considered that the plotting of R1 (Y-axis) versus R2 (X-axis) can provide useful information concerning the modes of action of flame retardant additives.

Figure 1 presents the results of more than 50 formulations tested in our laboratory at EMA. Polymers used were PMMA, EVA, PA6, PA12/SEBS blend and unsaturated polyester. Flame retardant additives or nanoparticles were alumina trihydrate $(\mathrm{ATH})$, magnesium dihydroxide $(\mathrm{MDH})$, boehmite $\mathrm{Al}(\mathrm{OOH})$, alumina $\mathrm{Al}_{2} \mathrm{O}_{3}$, titanium dioxide $\mathrm{TiO}_{2}$, silica nanoparticles, montmorillonite, ammonium 
polyphosphate, melamine polyphosphate, zinc borate, carbon nanotubes and combinations of two or three among them. It could be seen that in all cases, the points are plotted above the dotted line R1 = R2. This line corresponds to a similar decrease in PHRR in cone calorimeter and in PCFC. Therefore, this overview confirms basically our hypothesis: the pHRR decrease is always higher in cone calorimeter than in PCFC. Only some points are just below the line R1 = R2, probably due to the uncertainty of data.

In order to illustrate the use of this method, specific polymer additives systems will be scrutinized in the following. In these systems, no chemical flame inhibition is expected. Hence, it is suggested that the differences between results obtained from cone calorimeter and from PCFC could be ascribed to physical effects like mass or heat transfer barrier effects.

2- Materials

The polymers used in this study were: Ethylene Vinyl Acetate (Evatane 2805) with $28 \mathrm{wt} \%$ of vinyl acetate, Polyamide 6 (Domamid 24 from Arkema) and two Poly(methyl methacrylate) grades (Altuglas V825T and Altuglas BS9ELS).

Commercial FR systems were: micrometric MDH (Magnifin H10), Ammonium polyphosphate (Exolit AP423), nanosilica (Aerosil A200 and R805 from Evonik). Aerosil A200 is an untreated nanosilica whereas R805 surface was octylsilane-treated. Nanometric boehmite, nanometric alumina and lamellar and fibrous nanometric MDH were synthetized at laboratory scale. More details about this nanometric MDH can be found in reference [10]. PMMA-MWNT (multi-walled carbon nanotubes) 95-5 and PA6MWNT 80-20 were provided directly by Arkema.

\section{3- Processing}

Compositions were extruded using a Clextral BC21 twin-screw extruder and injection-moulded using a 50 Tons Krauss Maffei equipment. Processing conditions (temperature, screw profile, drying conditions) were selected in each case to obtain the best dispersion and to avoid the degradation of the polymer matrix.

Altuglas V825T PMMA was blended with nanometric MDH, alumina and boehmite using an internal mixer (Haake Rheomix) at $225^{\circ} \mathrm{C}(10 \mathrm{~min}$ at $50 \mathrm{rpm}$ ). The specimens for cone calorimeter tests were compression moulded at $250^{\circ} \mathrm{C}$ using an Agila PE20 hydraulic press.

4- Fire testing and characterization of microstructures 


\section{Results and Discussion}

1- Magnesium Dihydroxide (MDH)/EVA compositions

MDH is very often used in EVA at very high contents (up to $60 \mathrm{wt} \%$ ), particularly in the cable industry. At such contents, MDH acts in the condensed phase as a diluting filler (decreasing the amount of combustible material), and as well as a barrier component to limit mass and heat transfer by an endothermic action due to its thermal decomposition.

Figure 2 shows R1 versus R2 representation of EVA / MDH compositions. Because EVA exhibits two heat released rate peaks at PCFC test (Figure 3), only the sumHRC has been considered for R1 calculation. Nevertheless, if we take into account only the highest peak, similar results are obtained. It appears that the curve moves away from the line R1 = R2 when MDH content increases. The content for which there is a significant gap between the experimental curve $R 1=f(R 2)$ and the line $R 1=R 2$ could be estimated around 40-50wt\%. Then we could conclude that below this content, MDH acts only as a diluting filler and only through a cooling effect by releasing water. Above this content, a barrier effect could be assumed and this effect seems more and more pronounced as a function of loading.

The plotting of sumHRC versus MDH content proves that MDH acts only as a diluting effect in PCFC test conditions (Figure 4). The decrease in sumHRC corresponds only to the decrease in combustible phase when more $\mathrm{MDH}$ is incorporated. $\mathrm{MDH}$ releases water in the range of $300-400^{\circ} \mathrm{C}$, while the main pHRR of EVA is above $400^{\circ} \mathrm{C}$. Therefore, it can be concluded that the endothermic effect related to water release is not efficient enough to lower the decomposition rate of EVA investigated using this technique. 
Residues of these formulations obtained from "epiradiator test" (French standard NFP 92-505: $7 * 7 * 0.4 \mathrm{~cm}^{3}$ samples are exposed to a heating source (hemispheric radiator of $500 \mathrm{~W}$ ) confirm the existence of this barrier effect (Figure 5). This test was performed because it corresponds to a static fire degradation mode and because the radiator can be easily removed to observe the residue before complete degradation. No char barrier seems to limit the transfer of heat and/or gases even up to $40 \mathrm{wt} \%$ of MDH. A barrier effect could be possible for higher MDH content but it can be suggested that cracks present in the char layer could strongly reduce its efficiency.

It is proposed to calculate the contribution of the diluting effect and this of barrier effect in the decrease in pHRR. The decrease in sumHRC at PCFC could be fully attributed to the diluting effect of non combustible filler. The further decrease in cone calorimeter corresponds to the barrier effect. For example, for EVA-MDH 40-60, the decrease in sumHRC is 55\% in PCFC and the decrease in pHRR is $74 \%$ in cone calorimeter. Therefore, the respective contribution of diluting effect and endothermic release of water can be estimated to $(55 / 74) * 100=74 \%$ (vertical solid arrow in Fig.2) and the part of barrier effect is equal to [(74-55)/74] $* 100=26 \%$ (horizontal solid arrow in Fig.2).

\section{2- Boehmite/EVA compositions}

Boehmite is an aluminium monohydroxide which has emerged as FR additive, mainly under its submicronic form as a new hydrated filler.

Two kinds of boehmites (nano and microboehmite) were incorporated into EVA and tested according to the same fire test conditions (Figure 6). EVA-MDH points were plotted for the sake of comparison. All the points follow the same tendency observed for EVA-MDH. When the filler content increases, the experimental points move away from the line R1 = R2. The comparison between nano-and microboehmite shows that nano-boehmites are more efficient to lower pHRR, but only at low content (10$20 \mathrm{wt} \%)$. At higher content, no difference was observed: the nanoboehmites are probably aggregated leading to the formation of only a microcomposite structure.

The observation of residues after cone calorimeter test confirms that there is no difference between both kinds of boehmites (Figure 7).

We can also notice that boehmites behave more efficiently than MDH at the same filler content. This can be observed for both cone calorimeter and PCFC results. Therefore, the explanation for such a difference could not be attributed only to barrier effects. Boehmites do not act only as diluting fillers since a $10 \mathrm{wt} \%$ content leads to $16 \%$ decrease of HRC in PCFC test. Boehmite water release occurs from $400^{\circ} \mathrm{C}$ and overlaps the main decomposition step of EVA. Therefore, the influence of the 


\section{3- PMMA/nanoparticles compositions}

In a previous article [10], we incorporated 5-20wt\% of MDH nanoparticles in PMMA matrix Altuglas V825T. Nanoparticles were either lamellar or fibrous and the best results in cone calorimeter tests (35 $\mathrm{kW} / \mathrm{m}^{2}$ ) were obtained with lamellar MDH. We concluded that the main effect of MDH was a charpromoting effect in all cases.

In Figure 9, R1 is plotted versus R2 for PMMA/nano-MDH systems and for some other new systems tested in the same conditions. The new fillers include two nano-alumina (alpha and gamma) and one nano-boehmite, synthetized at laboratory scale. PMMA shows only one peak of heat release rate in PCFC and thus the HRC is equal to the pHRR when analysis is performed at $1 \mathrm{~K} / \mathrm{s}$. It appears that all the formulations could be divided in two categories. For PMMA-nanoMDH (lamellar and fibrillar), all the experimental points are very close to the line $\mathrm{R} 1=\mathrm{R} 2$. Some points are just below this line, due to the uncertainty of data. Even at $20 \mathrm{wt} \%$ of nano-MDH, the decrease in pHRR is the same for cone calorimeter results and PCFC results. We could conclude that no barrier effect is involved with both nano-MDH at these contents.

On the contrary, for PMMA/nanoboehmite and PMMA/nanoalumina, the decrease in pHRR at cone calorimeter is stronger than this obtained at PCFC: R2 $<\mathrm{R} 1$. We could assume that a strong barrier effect happens for these systems.

The observation of the residues after cone calorimeter tests confirms once again this interpretation. Residues of PMMA-nanoMDH (Figure 10) are powdered residues and therefore no barrier effect could be expected. On the contrary, for PMMA-nanoalumina and nanoboehmite, the residues present a cohesive char layer (Figure 11) which could limit the heat transfer from the flame to the remaining polymer and the gases transfer from the pyrolysis zone to the flame.

4- PMMA /FR systems

Altuglas V825T has been flame retarded with a FR system based on ammonium polyphosphate (Exolit AP423) and nanosilica (from Evonik). Two nanosilica were used: A200 (hydrophilic nanosilica) and 
R805 (hydrophobic nanosilica). The content of FR system was fixed at $15 \mathrm{wt} \%$. The formulations were tested using PCFC and cone calorimeter (at $50 \mathrm{~kW} / \mathrm{m} 2$ ). Results are summarized in Figure 11.

Only AP423 is not efficient to reduce significantly the pHRR. The decrease in pHRR with $15 \mathrm{wt} \%$ AP423 is only $11 \%$ in PCFC and $16 \%$ in cone calorimeter and therefore we could conclude that AP423 at this percentage acts just as a diluting compound. Nanosilica are more efficient i.e. the decrease in pHRR is $15-20 \%$ in PCFC and $40 \%$ in cone calorimeter. A significant barrier effect could be assumed.

However, results are clearly more interesting when AP423 and nanosilica are used together. The decrease in pHRR is only $10-12 \%$ in PCFC but $45-55 \%$ in cone calorimeter. A strong barrier effect allows the pHRR in cone calorimeter to be lowered, in particular when hydrophobic R805 is used in combination with AP423.

The structuration of the residues formed during cone calorimeter test is coherent with these results (Figure 12). Residues for PMMA/nano-silica 85-15 are powdered and the barrier effect seems to be very limited. On the contrary, for PMMA/AP423-A200, the residue shows a cohesive but not expanded structure. For PMMA/AP423-R805, the residue is cohesive, expanded and flaky. This last structure seems very efficient to improve the insulation of the underlying material and can account for the better results obtained in this case.

The synergistic effect obtained when both nano-silica and AP423 are combined is ascribed to the formation of a $\mathrm{SiP}_{2} \mathrm{O}_{7}$ crystalline phase, observed by X-Ray diffraction [11] and formed by the reaction of both additives during pyrolysis. $\mathrm{SiP}_{2} \mathrm{O}_{7}$ could trap aromatic compounds and other degradation products and promote the formation of charred species, especially stable polyaromatic species.

The difference between PMMA/AP423+A200 and PMMA/AP423+R805 could be related to the dispersion of nano-silica in the PMMA matrix. STEM observations show clearly the presence of aggregated hydrophilic A200 nanosilica. On the contrary, for PMMA/AP423+R805, silica nanoparticles are better dispersed, forming only small aggregates. This better dispersion allows R805 and $\mathrm{AP} 423$ reacting to a large extent during pyrolysis, leading to a much higher amount of $\mathrm{SiP}_{2} \mathrm{O}_{7}$ crystalline phase

\section{5- Polymer-carbon nanotubes}

Even at very low content, carbon nanotubes are well known to decrease the pHRR of polymer nanocomposites during cone calorimeter test. Various phenomena were reported in literature to explain this behaviour but the most important effect is the formation of a randomly interlaced network structure mainly consisting of the CNT, which acts as a heat shield [12-14]. Moreover, to obtain a 
The plotted points start to move away from the line $\mathrm{R} 1=\mathrm{R} 2$ even before $0.2 \mathrm{wt} \%$ of $\mathrm{CNT}$, which is representative of an efficient barrier effect, according to our method. This result confirms that CNT could decrease drastically the heat release rate of a polymer, even at very low content, precisely because of the so-called barrier effect.

We could also notice that the decrease in pHRR in cone calorimeter (according to R2 value) is higher in the case of PA6 nanocomposites in comparison with that observed for PMMA nanocomposites. In particular, for $1 \mathrm{wt} \%$ of carbon nanotubes, the $\mathrm{R} 1$ value is approximately the same for both matrices but R2 value is lower for PA6 matrix. Therefore, we could conclude that the barrier effect is slightly more pronounced in the case of PA6 nanocomposites.

This observation could be related to the dispersion state of carbon nanotubes. Kashiwagi et al. [13-14] have shown that the decrease in pHRR in cone calorimeter for PMMA-CNT depends strongly on the quality of the CNT dispersion in the polymer matrix. In the Figure 15, STEM observations of PMMA and PA6 with $1 \mathrm{wt} \%$ of CNT are shown. It is obvious that the CNT are not well dispersed in the PMMA matrix. Big aggregates could be noticed. On the contrary, CNT are better dispersed in PA6 matrix. Only small aggregates are observed.

However, we could notice that the decrease in pHRR in PCFC could not be related to a diluting effect of CNT, because the CNT content is really negligible to dilute the combustible PMMA or PA6 phase. In Figure 16 we plot the relative pHRR in PCFC versus the CNT content: a decrease of 9 or $11 \%$ using $0.2 \mathrm{wt} \% \mathrm{CNT}$ and $12 \%$ using $1 \mathrm{wt} \% \mathrm{CNT}$ could be noticed. This result indicates that CNT acts as a flame retardant compound according to an effect which could be effective in the PCFC test conditions. Among the various modes of action of CNT mentioned in literature, only the trapping of radicals could have an influence in PCFC test conditions [15]. CNT are never pure and contain always moieties as fullerene or trace metals like iron particles from the residual catalyst $[9,13]$ even after purification. These moieties could trap radicals and explain the significant decrease in pHRR observed in PCFC test conditions. 


\section{Conclusions}

In this article, a new empirical method allowing the determination of the mode of action of flame retardant systems is proposed. The method consists in analyzing the mismatch between normalized pHRR data obtained in both PCFC and cone calorimeter tests.

As evidenced by the in-depth study of various kinds of flame retardant compositions of micro or nano-composites, cone calorimeter normalized pHRR (R2) is always lower than or equal to PCFC normalized pHRR (R1). When a mismatch between R1 and R2 was observed, the presence of protective barrier was also highlighted. Therefore, it was suggested that a mismatch between R1 and R2 could be a good indicator of the formation of protective layers, resulting in heat and mass transfer barrier effects.

One condition for such conclusion is that the thermal stability of the formulations in comparison is roughly the same (which is the case in our work). Indeed a difference in thermal stability would not have any effect in pHRR measured in PCFC while this parameter should have a great impact on pHRR in cone calorimeter.

From a general point of view, attempts aiming to estimate cone calorimeter test results from PCFC results failed to account for all the features of the fire behaviour, due to the difference in test conditions. A more relevant approach consists in analyzing the mismatch between results of both techniques taking into account the test conditions, in order to establish the influence of various parameters. In the present work, barrier effects were specifically studied, but other phenomena could be investigated according to a similar approach.

\section{Acknowledgments}

The authors are grateful to François Ganachaud, Lucie Tibiletti, Yen Quach, Khushboo Rinawa, Sylvain Buonomo and Benjamin Gallard for their help.

\section{References}

[1] F. Laoutid, L. Bonnaud, M. Alexandre, J. M. Lopez-Cuesta, P. Dubois, Materials Science and Engineering Reports 63 (2009) 63, 100-125

[2] R.E. Lyon, R.N. Walters, J. Anal. Appl. Pyrolysis 71 (2004), 27-46

[3] R.N. Walters, R.E. Lyon, Journal of Applied Polymer Science 87 (2003), 548-563 
[4] R.E. Lyon, M.T. Takemori, N. Safronava, S.I. Stoliarov, R.N. Walters, Polymer 50 (2009), 26082617

[5] C.Q. Yang, Q. He, R.E. Lyon, Y. Hu, Polymer Degradation and Stability 95 (2010), 108-115

[6] A.B. Morgan, M. Galaska, Polymers for Advanced Technologies 19 (2008), 530-546

[7] B. Schartel, K.H. Pawlowski, R.E. Lyon, Thermochimica Acta 462 (2007), 1-14

[8] J.M. Cogen, T.S. Lin, R.E. Lyon, Fire and Materials 33 (2009), 33-50

[9] H. Lu, C.A. Wilkie, Polymer Degradation and Stability 95 (2010), 564-571

[10] F. Laoutid, R. Sonnier, D. François, L. Bonnaud, N. Cinausero, J-M. Lopez-Cuesta, P. Dubois, Polymers for Advanced Technologies, published online (2010)

[11] N. Cinausero, Etude de la dégradation thermique et de la réaction au feu de nanocomposites à matrice PMMA et PS, PhD thesis, Université de Montpellier II, France (2008), 273 p

[12] B.H. Cipiriano, T. Kashiwagi, S.R. Raghavan, Y. Yang, E.A. Grulke, K. Yamamoto, J.R. Shields, J.F. Douglas, Polymer 48 (2007), 6086-6096

[13] T. Kashiwagi, F. Du, K.I. Winey, K.M. Groth, J.R. Shields, S.P. Bellayer, H. Kim, J.F. Douglas, Polymer 46 (2005), 471-481

[14] T. Kashiwagi, J. Fagan, J.F. Douglas, K. Yamamoto, A.N. Heckert, S.D. Leigh, J. Obrzut, F. Du, S. Lin-Gibson, M. Mu, K.I. Winey, R. Haggenmueller, Polymer 48 (2007), 4855-4866

[15] S. Peeterbroeck, F. Laoutid, B. Swoboda, J.-M. Lopez-Cuesta, N. Moreau, J. B. Nagy, M. Alexandre, Ph. Dubois, Macromol. Rapid Commun. 28 (2007), 260-264 


\section{Figures}

\begin{tabular}{|c|c|}
\hline Figure 1 & $\mathrm{R} 1$ versus $\mathrm{R} 2$ for various flame retardant polymers \\
\hline Figure 2 & $\begin{array}{l}\text { R1 versus R2 representation for a EVA-MDH system (MDH content is } \\
\text { indicated on the graph) }\end{array}$ \\
\hline Figure 3 & HRR versus Temperature for EVA in PCFC analysis \\
\hline Figure 4 & sumHRC versus MDH content for EVA-MDH systems \\
\hline Figure 5 & EVA-MDH residues after epiradiator test (MDH content below each residue) \\
\hline Figure 6 & $\begin{array}{l}\text { R1 versus R2 for EVA-boehmite (filler content: } 10,20,30,40,50 \mathrm{wt} \% \text { ) and } \\
\text { EVA-MDH (filler content: } 20,40,50,55,60,65 \mathrm{wt} \% \text { ) }\end{array}$ \\
\hline Figure 7 & $\begin{array}{l}\text { Residues for EVA-boehmite 60-40 after cone calorimeter tests (left: EVA } \\
\text { with nanoboehmites ; right: EVA with microboehmites) }\end{array}$ \\
\hline Figure 8 & $\begin{array}{l}\text { HRR (a), Heat evolved by mass loss unity (b) and mass loss rate (c) versus } \\
\text { time in cone calorimeter for EVA-microboehmite } 70-30\end{array}$ \\
\hline Figure 9 & $\begin{array}{l}\text { R1 versus R2 representation for PMMA-nanofillers systems: PMMA-nano- } \\
\text { boehmite (filler content: 5, 10, 20\%), PMMA-alpha and gamma nano- } \\
\text { alumina (filler content 20\%), PMMA-fibrous and lamellar nanoMDH (filler } \\
\text { content: } 5,10,20 \% \text { ) }\end{array}$ \\
\hline Figure 10 & Residues of PMMA-nanofiller 80-20 after cone calorimeter tests \\
\hline Figure 11 & R1 versus R2 for PMMA + 15wt\% FR systems \\
\hline Figure 12 & Residues of PMMA+15wt\% FR systems after cone calorimeter tests \\
\hline Figure 13 & STEM observations of PMMA+AP423+nanosilica \\
\hline Figure 14 & $\begin{array}{l}\text { R1 versus } \mathrm{R} 2 \text { representation for PMMA and PA6 containing carbon } \\
\text { nanotubes (NTC content: } 0.2 \text { and } 1 \mathrm{wt} \% \text { ) }\end{array}$ \\
\hline Figure 15 & STEM observations of PMMA-CNT (left) and PA6-CNT (right) \\
\hline Figure 16 & $\begin{array}{l}\text { Relative pHRR in PCFC versus CNT content for PMMA-CNT and PA6- } \\
\text { CNT }\end{array}$ \\
\hline
\end{tabular}


Figure 1 - R1 versus R2 for various flame retardant polymers

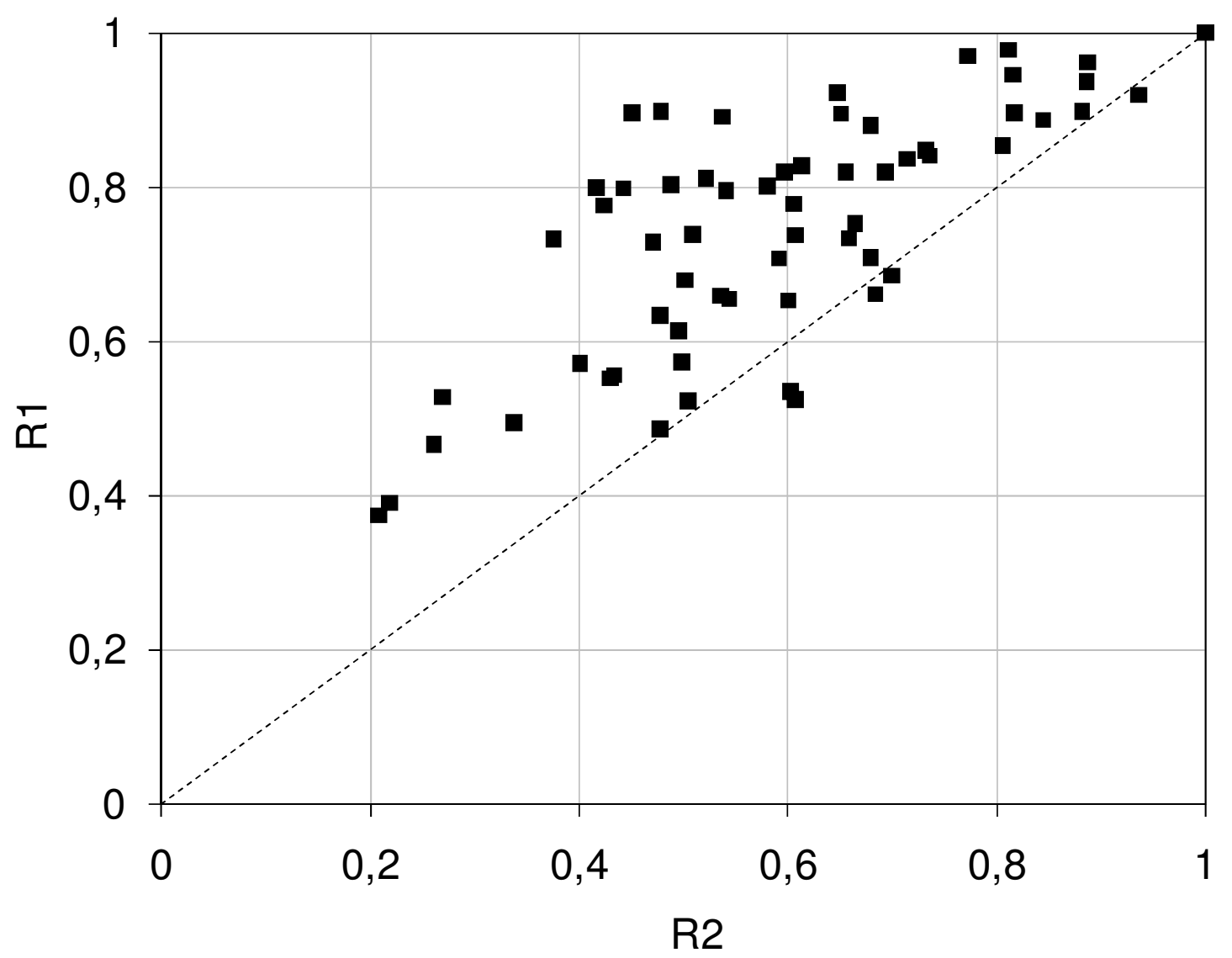


Figure 2 - R1 versus R2 representation for a EVA-MDH system (MDH content is indicated on the graph)

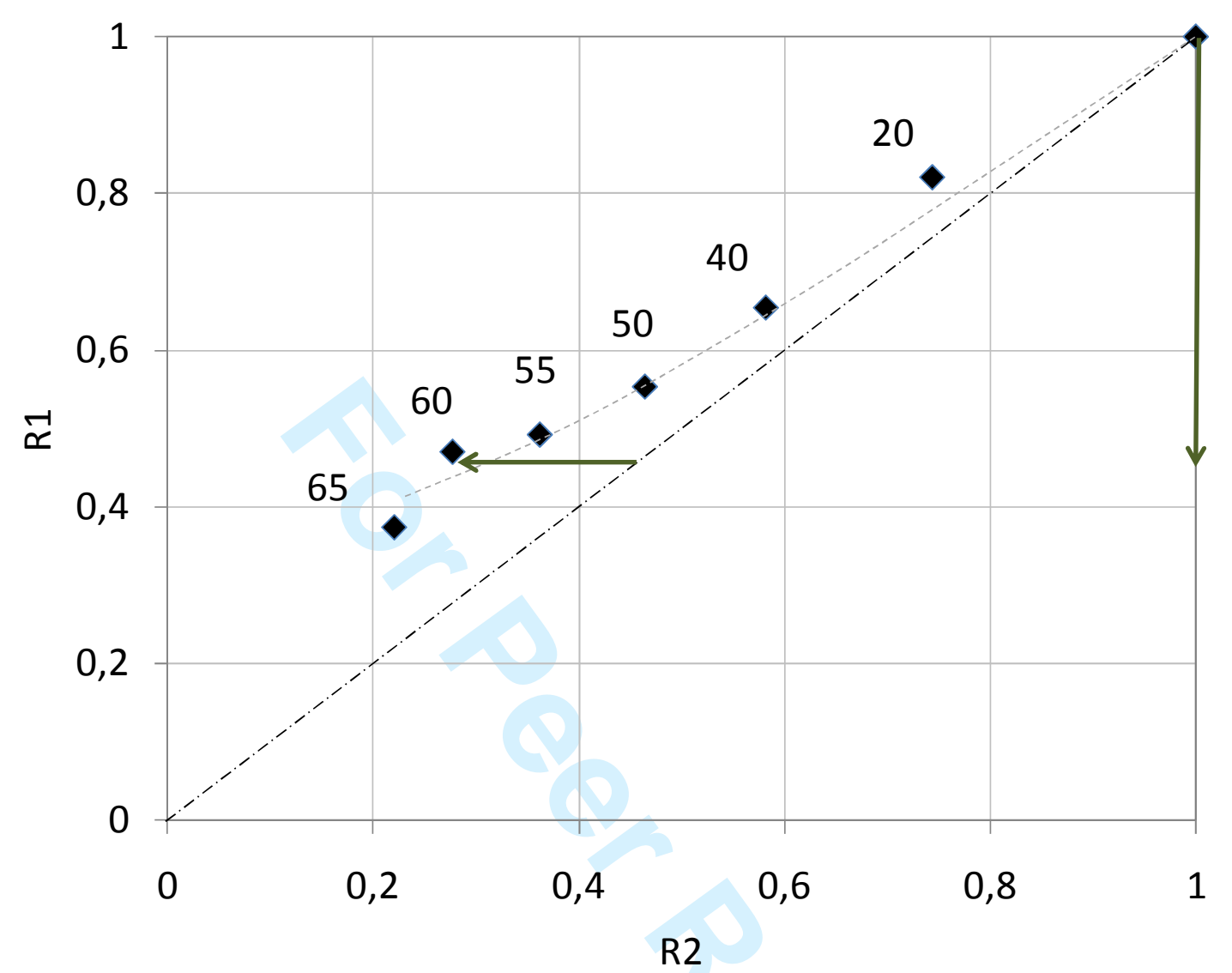


Figure 3 - HRR versus Temperature for EVA in PCFC analysis

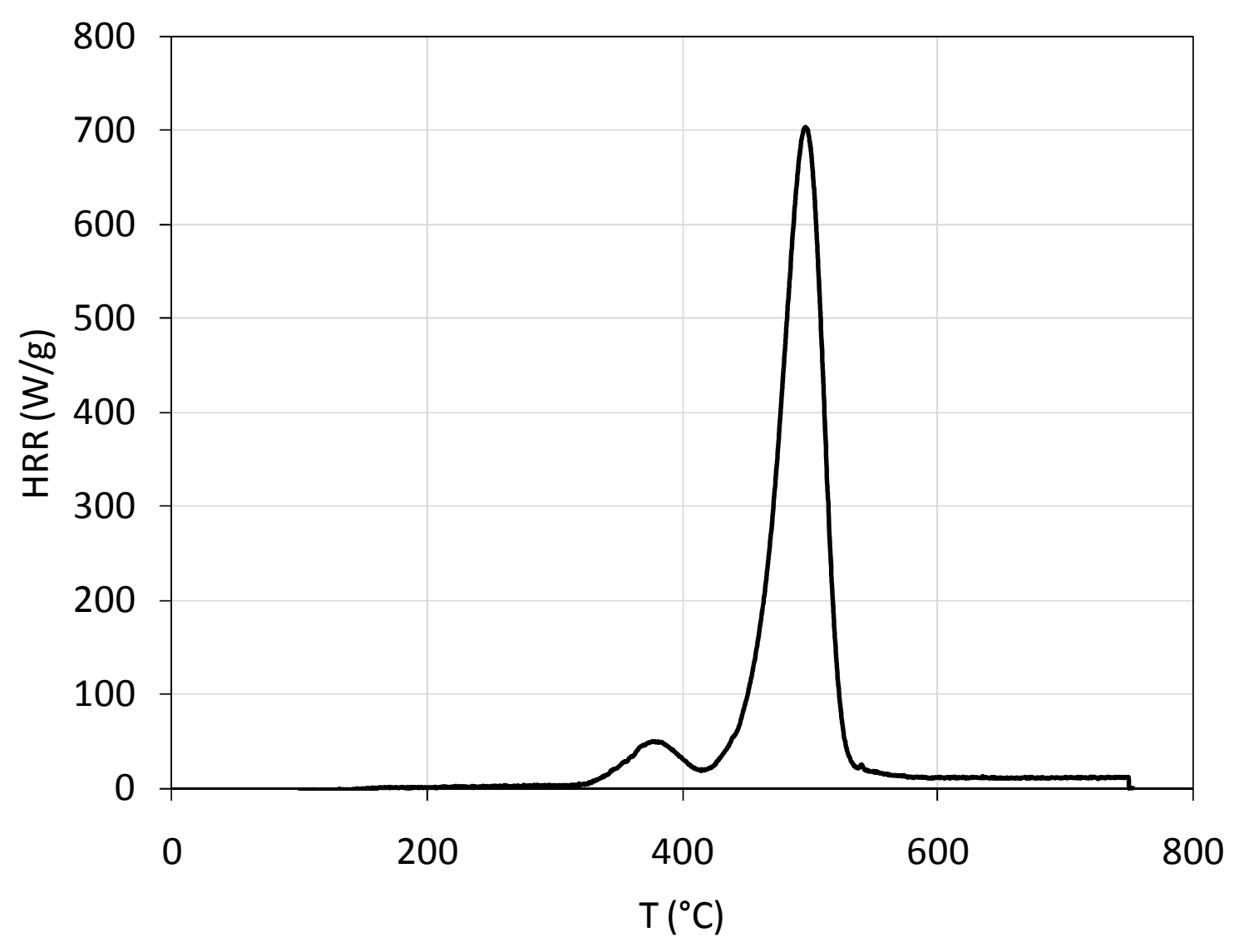


Figure 4 - sumHRC versus MDH content for EVA-MDH systems

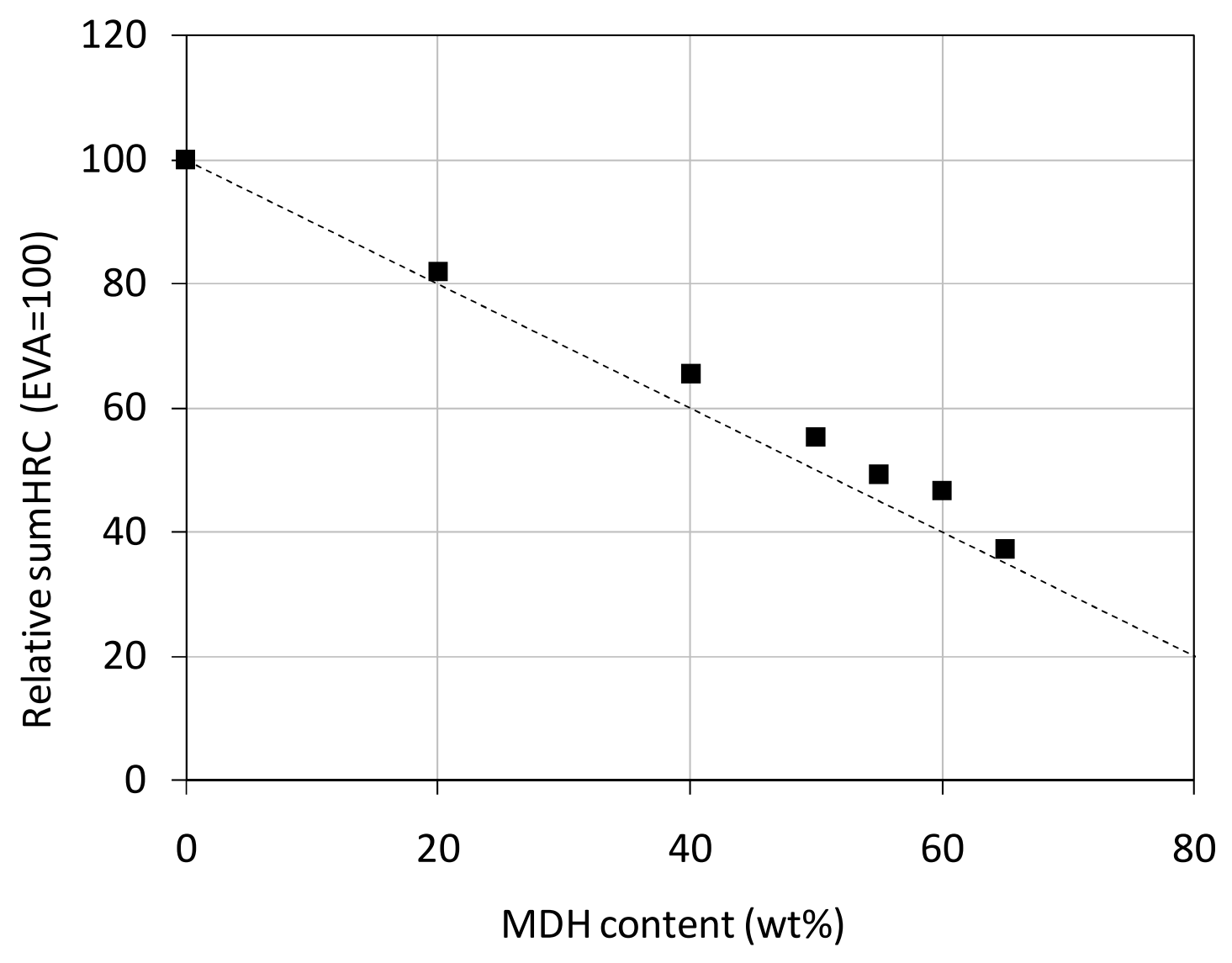


Figure 5 - EVA-MDH residues after epiradiator test (MDH content below each residue)

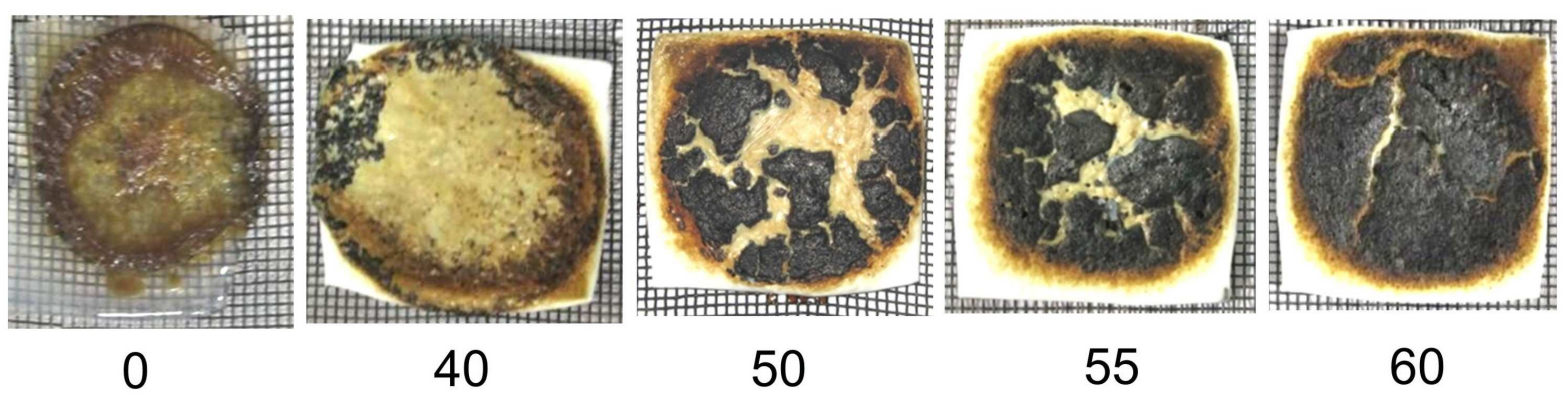


Figure 6 - R1 versus R2 for EVA-boehmite (filler content: 10, 20, 30, 40, $50 \mathrm{wt} \%$ ) and EVAMDH (filler content: 20, 40, 50, 55, 60, $65 \mathrm{wt} \%$ )

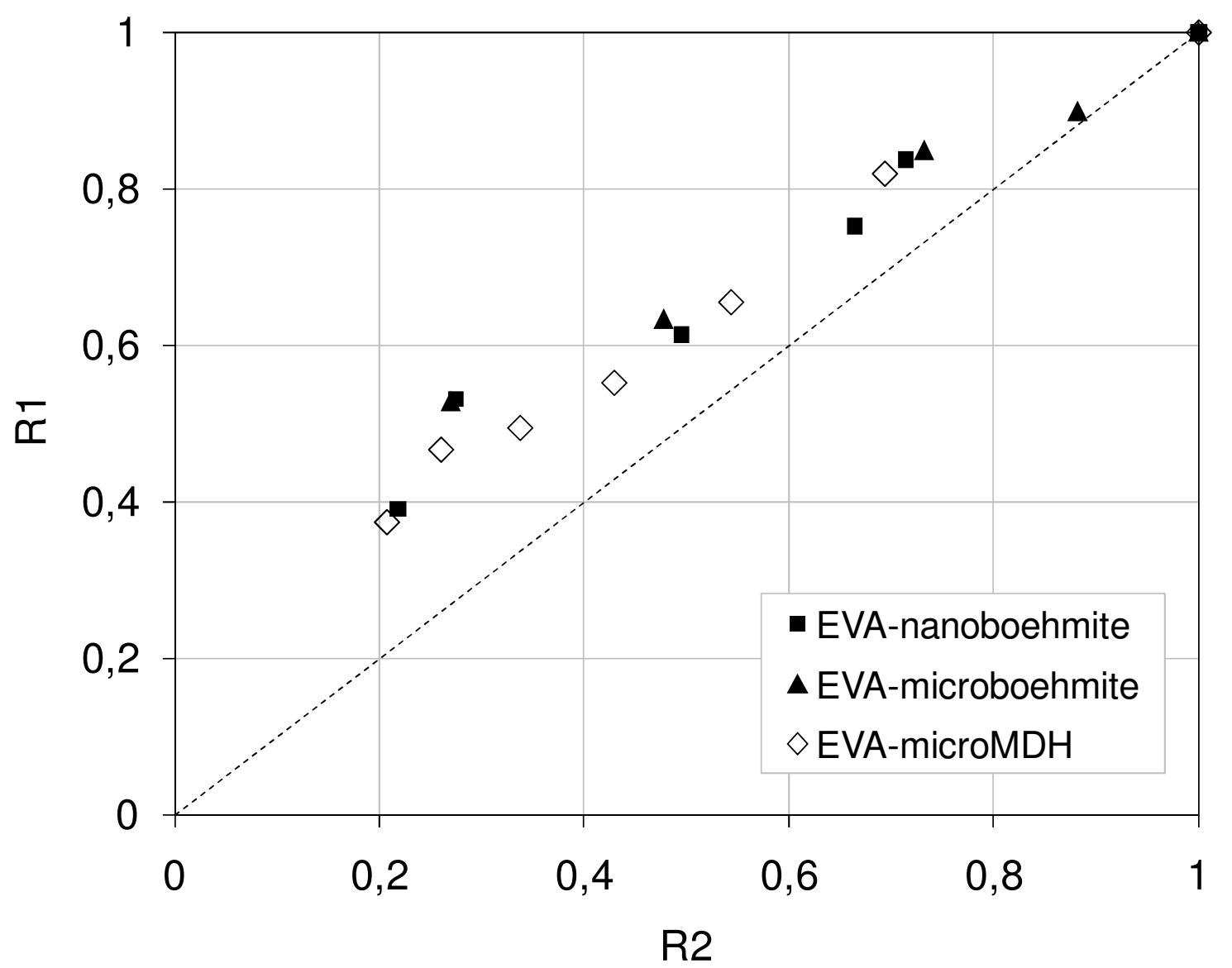


Figure 7 - Residues for EVA-boehmite 60-40 after cone calorimeter tests (left: EVA with nanoboehmites ; right: EVA with microboehmites)

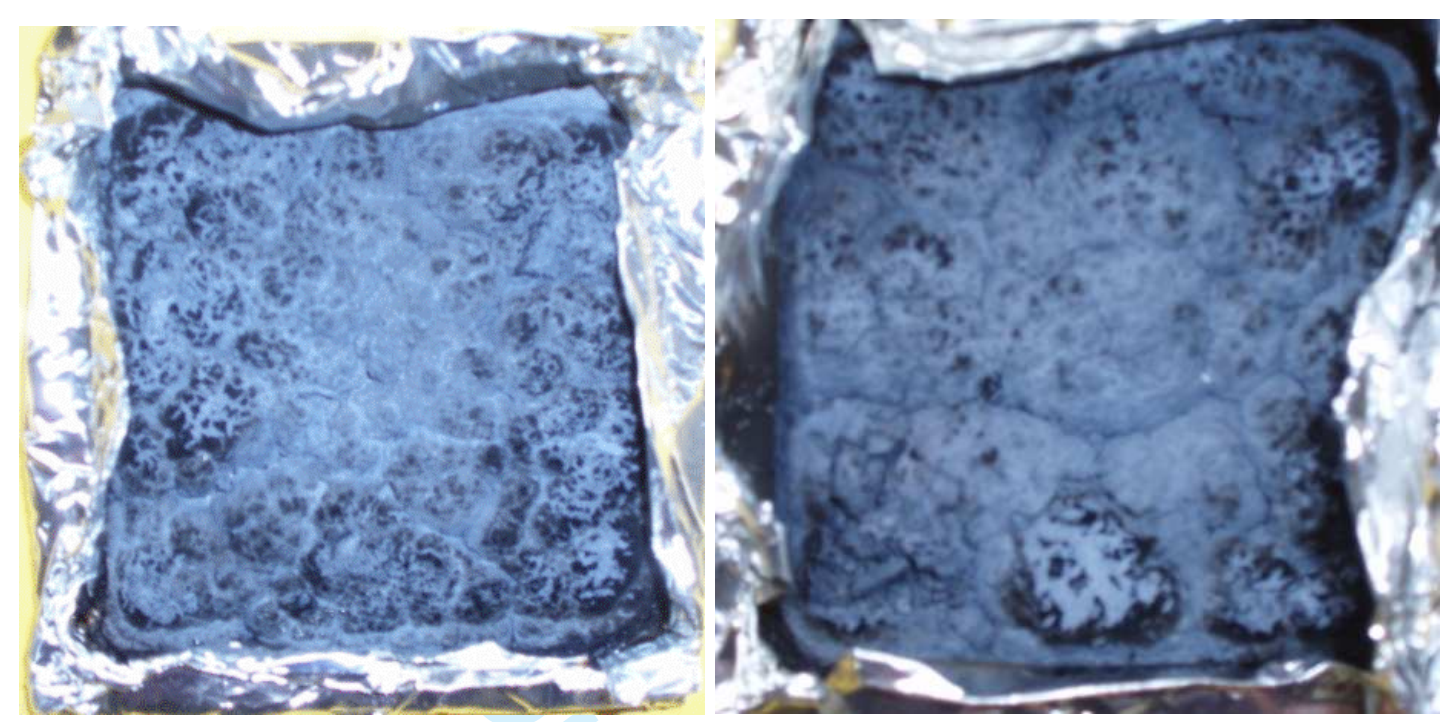


Figure 8 - HRR (a), Heat evolved by mass loss unity (b) and mass loss rate (c) versus time in cone calorimeter for EVA-microboehmite 70-30

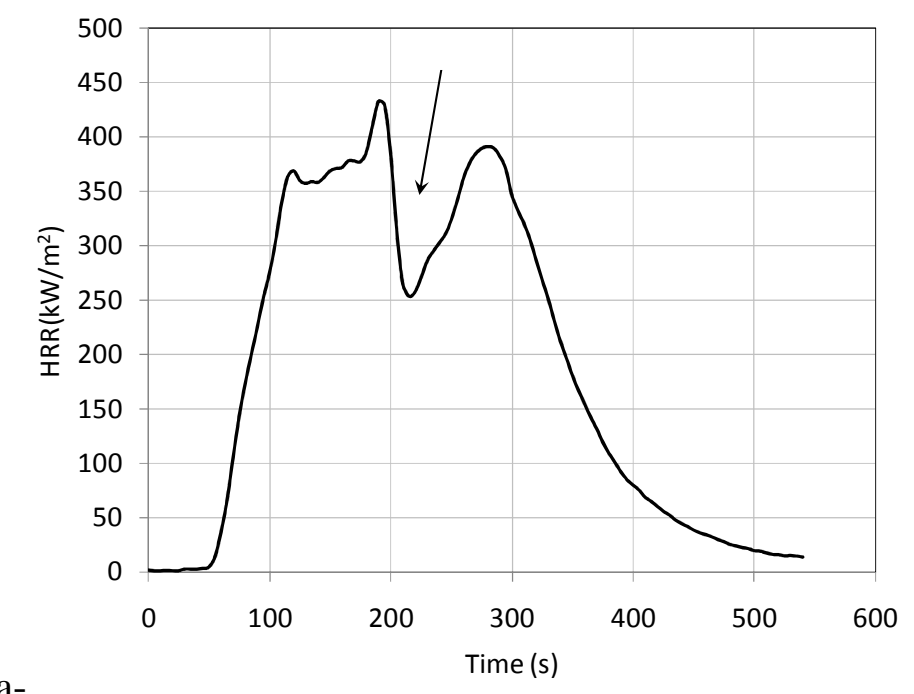

a-

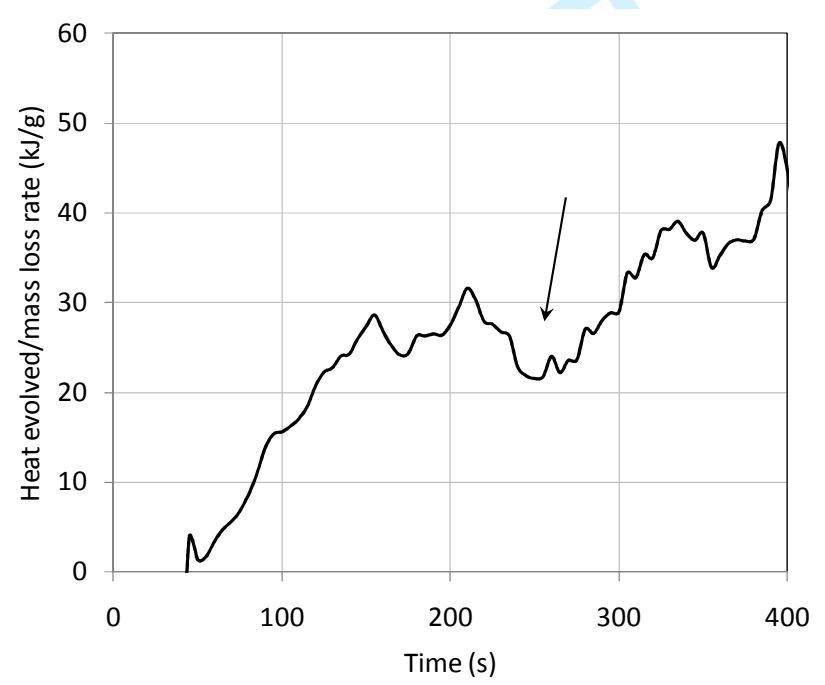

b-

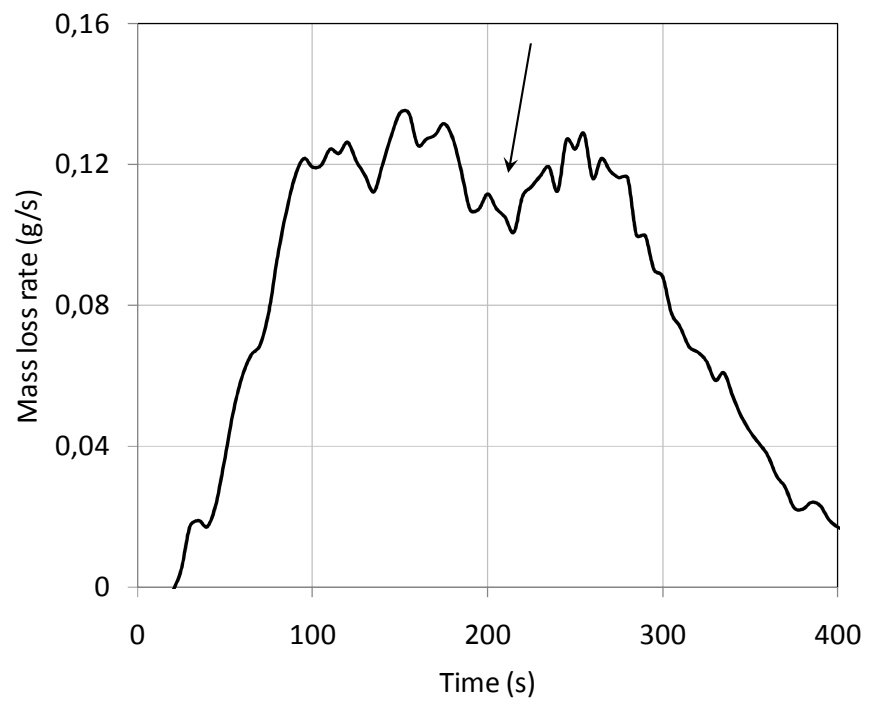

c- 
Figure 9 - R1 versus R2 representation for PMMA-nanofillers systems: PMMA-nanoboehmite (filler content: 5, 10, 20\%), PMMA-alpha and gamma nano-alumina (filler content 20\%), PMMA-fibrous and lamellar nanoMDH (filler content: 5, 10, 20\%)

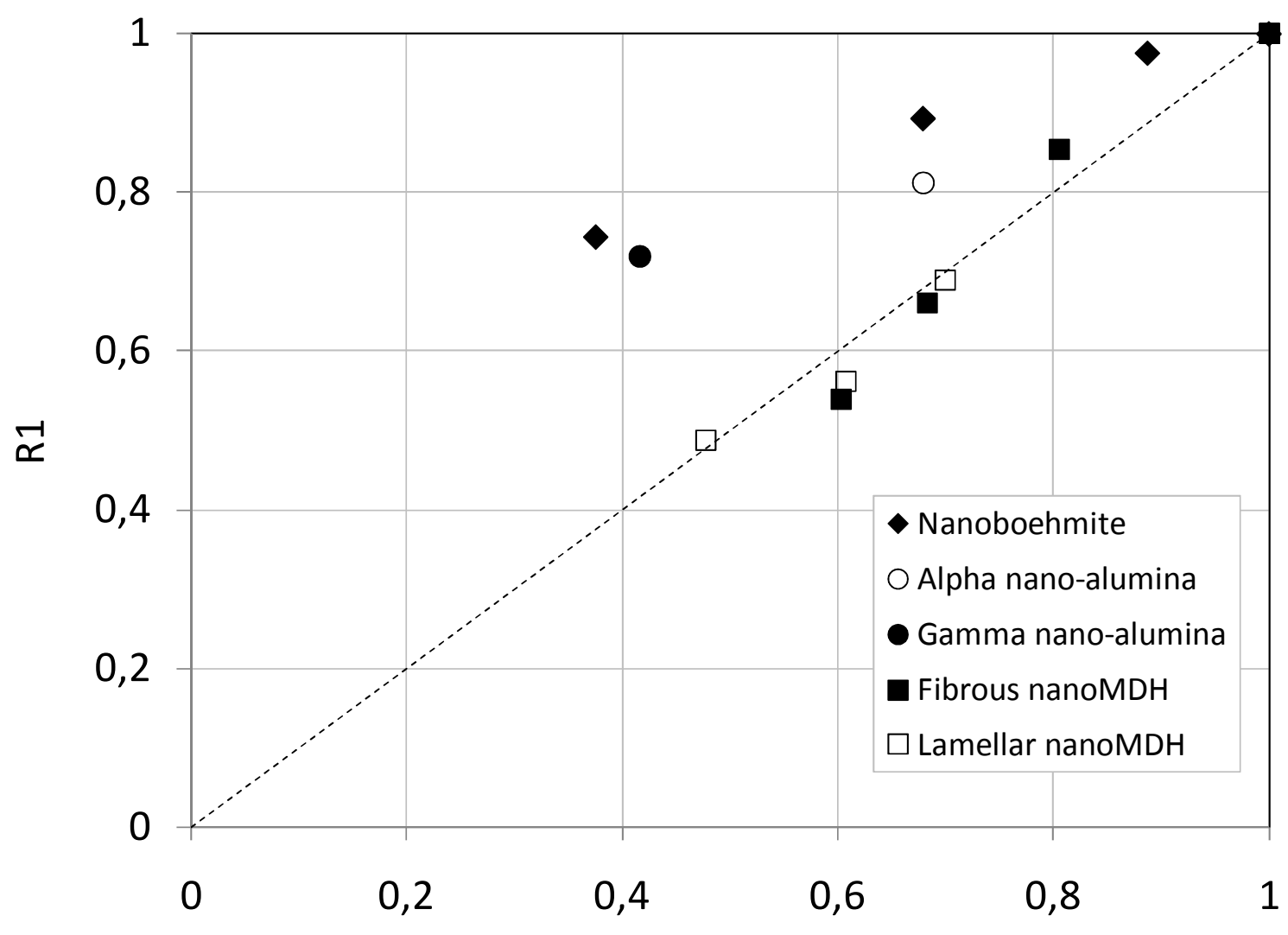

R2 
Figure 10 - Residues of PMMA-nanofiller 80-20 after cone caloirmeter tests

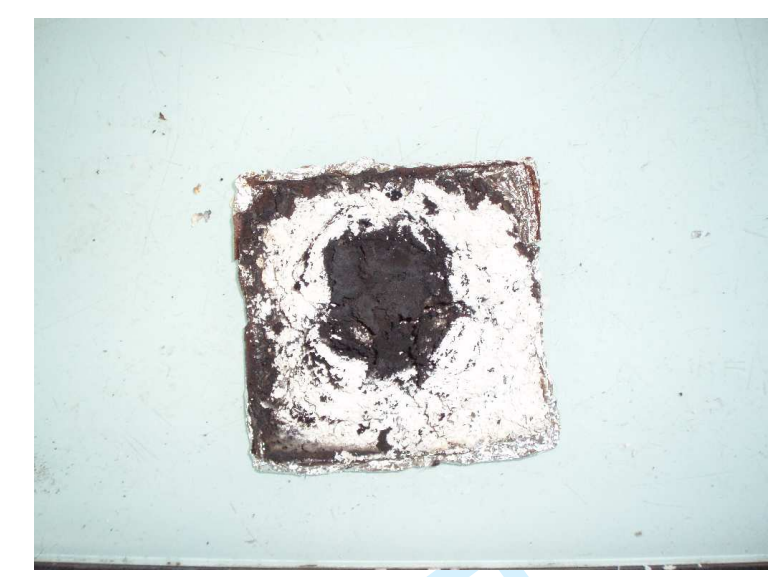

a- PMMA-lamellar nanoMDH 80-20

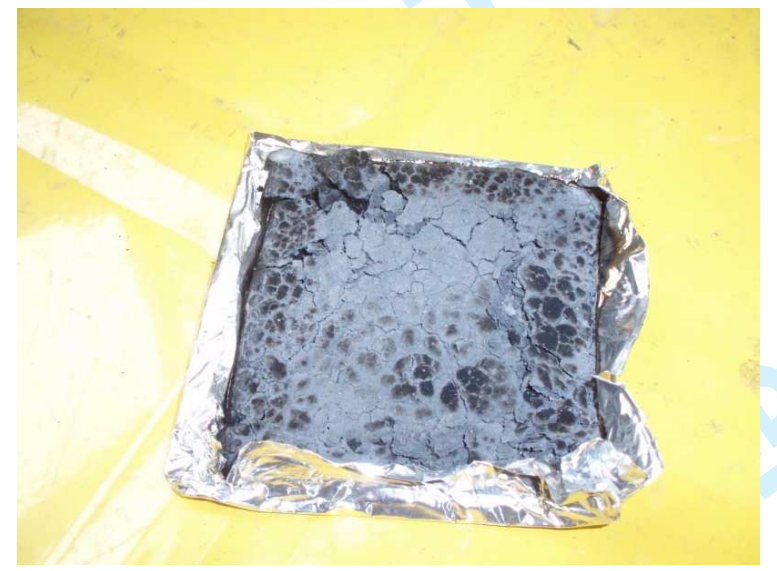

c- PMMA-nanoboehmite 80-20

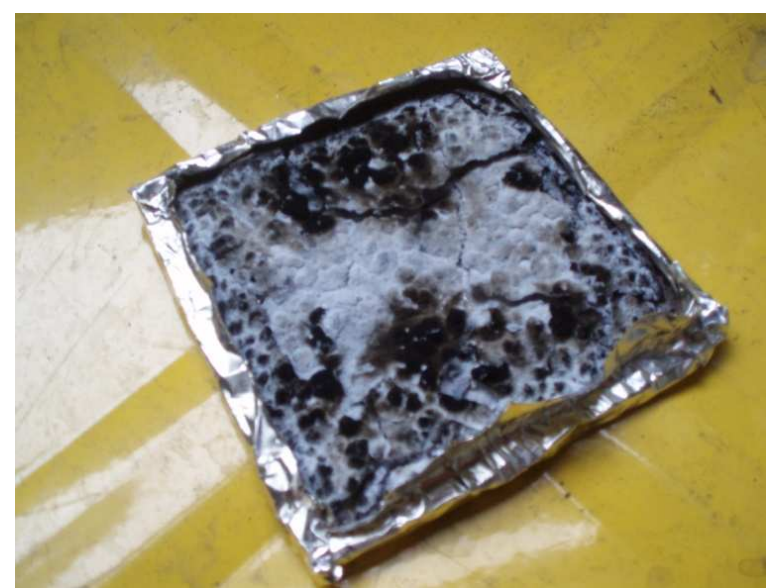

e- PMMA-alpha nanoalumina 80-20

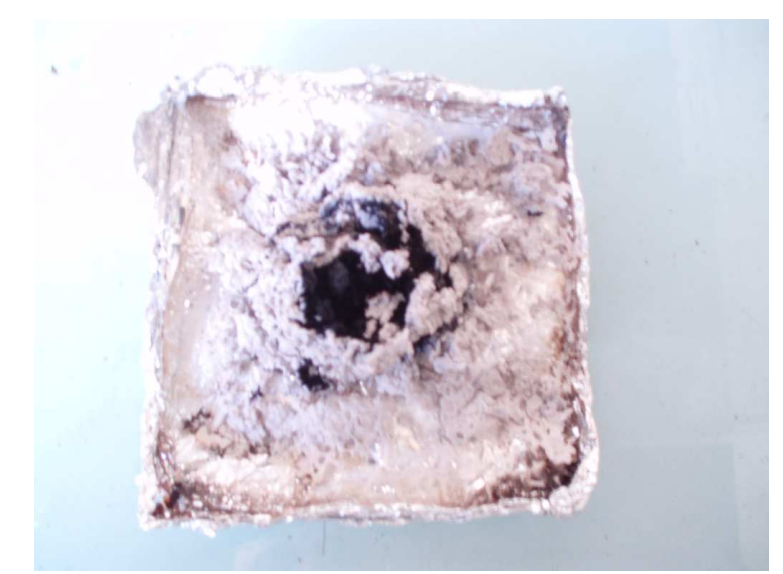

b- PMMA-fibrous nanoMDH 80-20

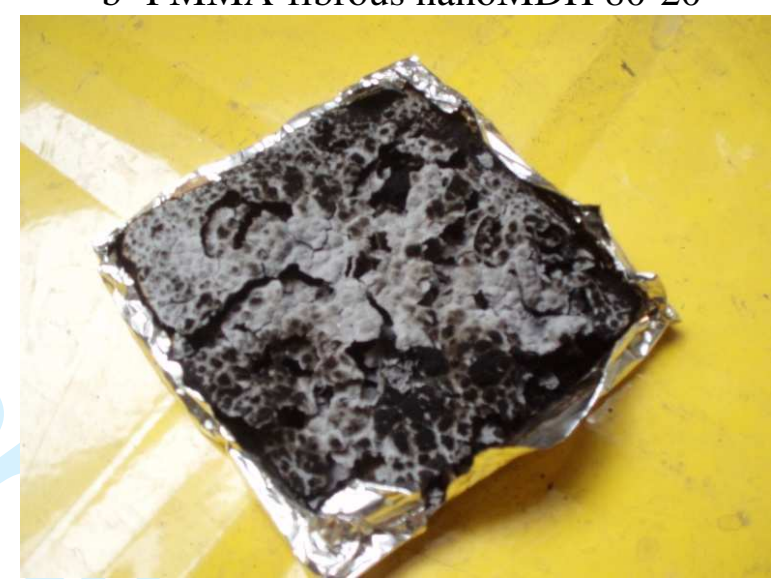

d- PMMA-gamma nanoalumina 80-20 
Figure 11 - R1 versus R2 for PMMA + 15wt\% FR systems

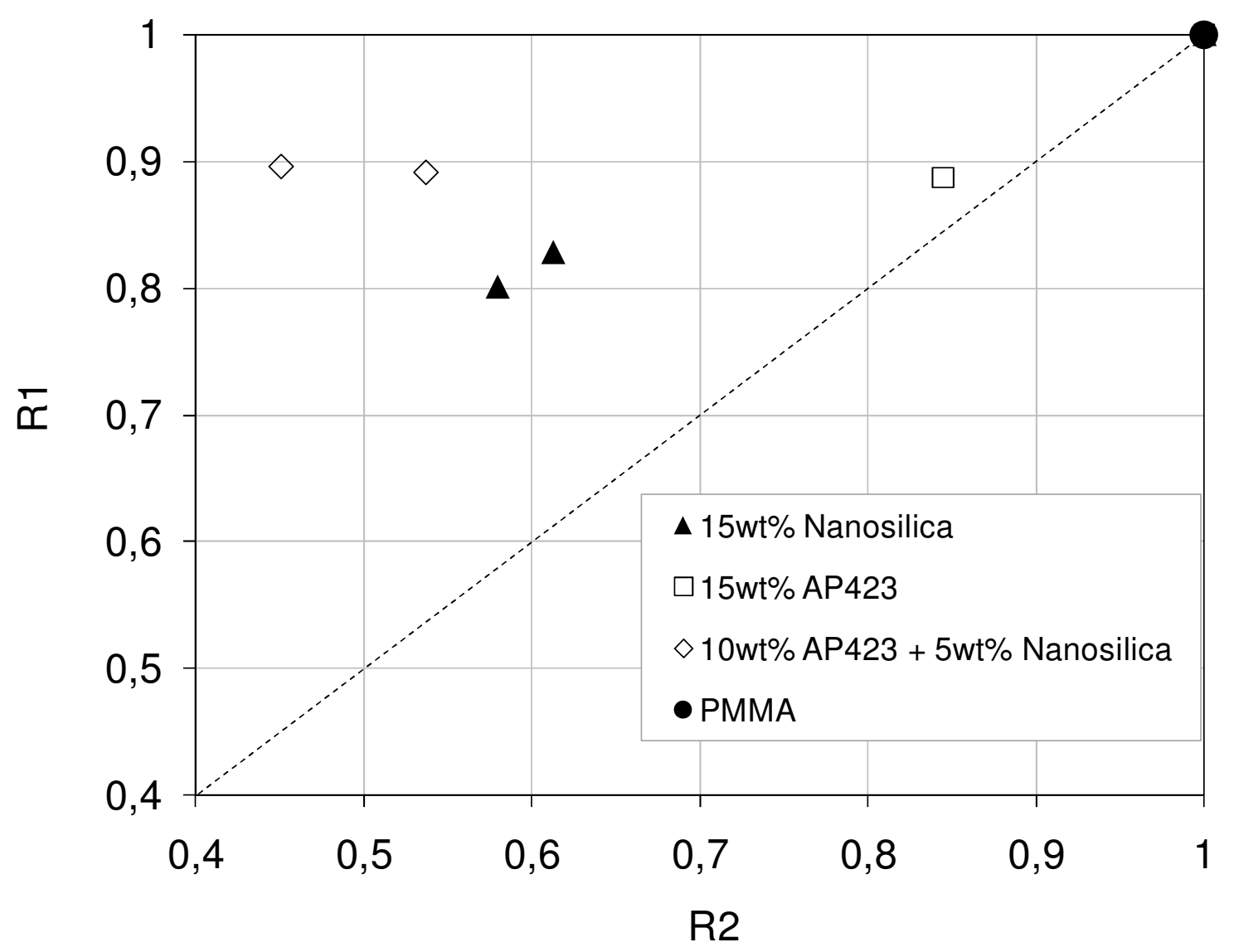


Figure 12 - Residues of PMMA+15wt\% FR systems after cone calorimeter tests

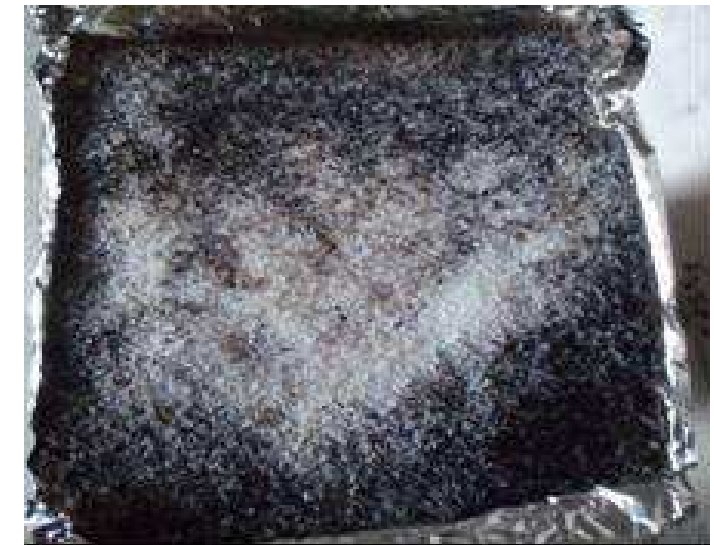

a- PMMA+15wt\% A200

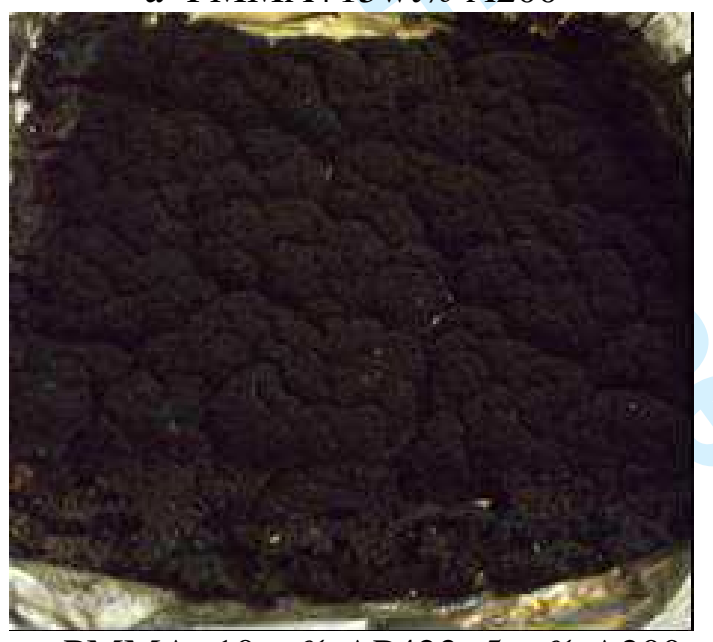

c- PMMA+10wt\% AP423+5wt\% A200

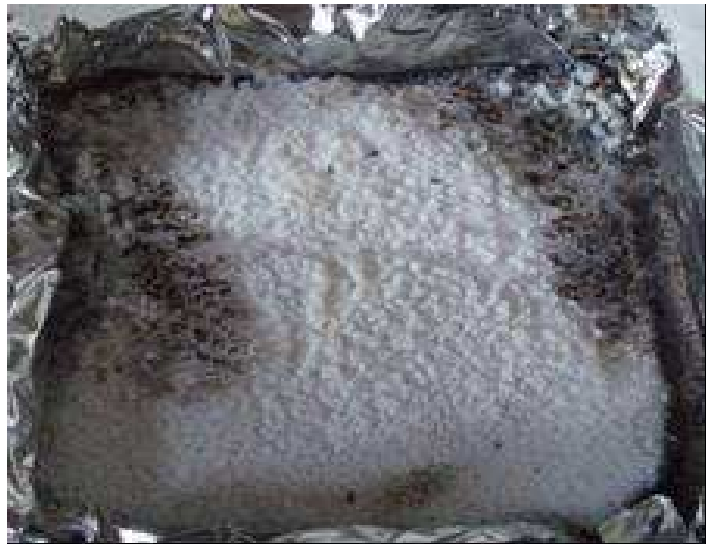

b- PMMA+15wt $\%$ A200

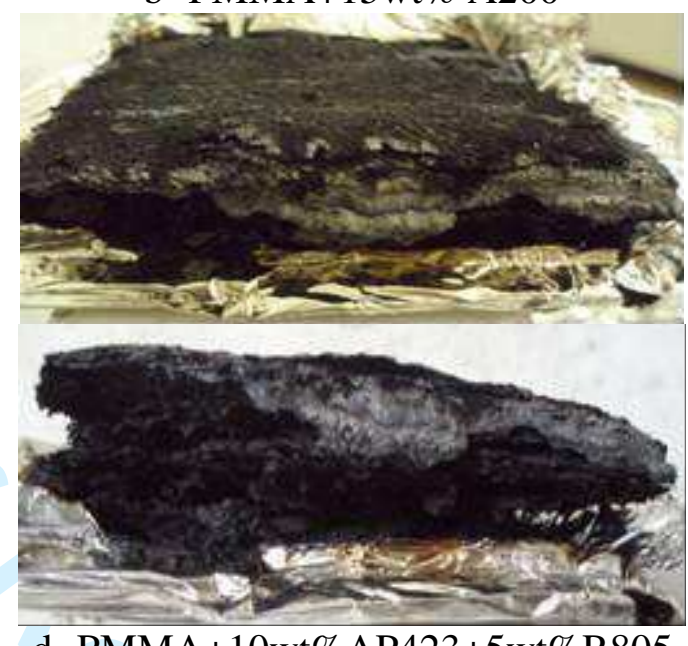

d- PMMA+10wt\%AP423+5wt\%R805 
Figure 13 - STEM observations of PMMA+AP423+nanosilica

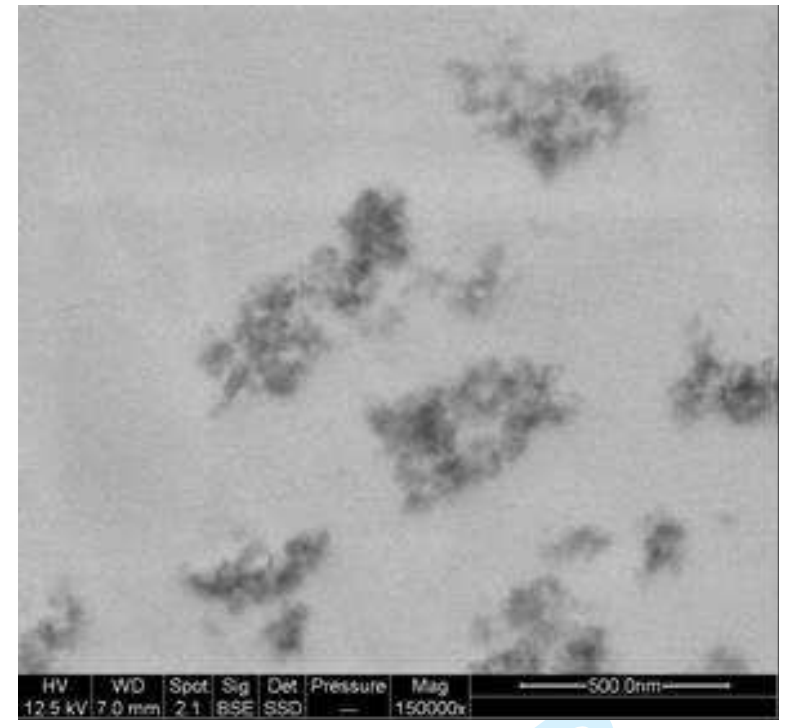

a- PMMA+AP423+A200

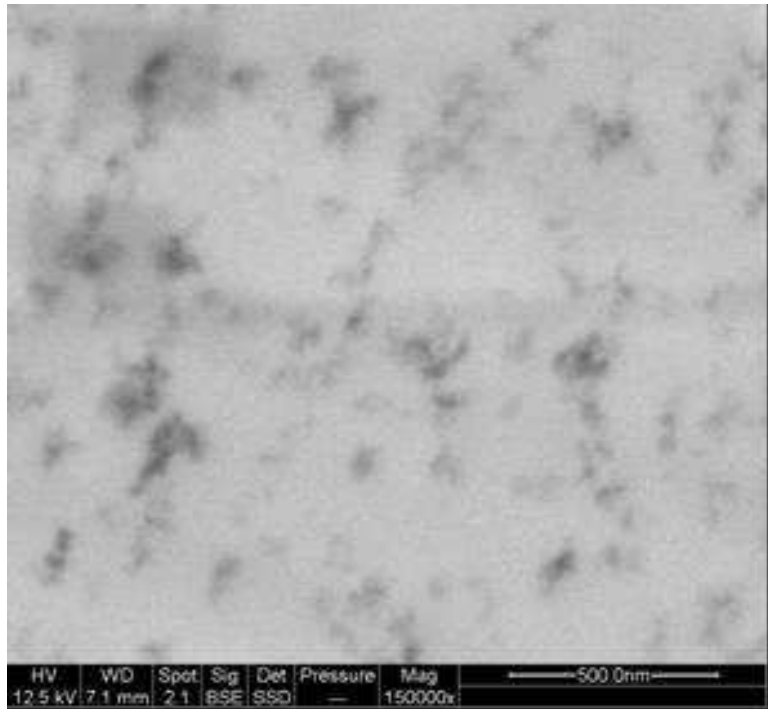

b- PMMA+AP423+R805 
Figure 14 - R1 versus R2 representation for PMMA and PA6 containing carbon nanotubes (NTC content: 0.2 and $1 \mathrm{wt} \%$ )

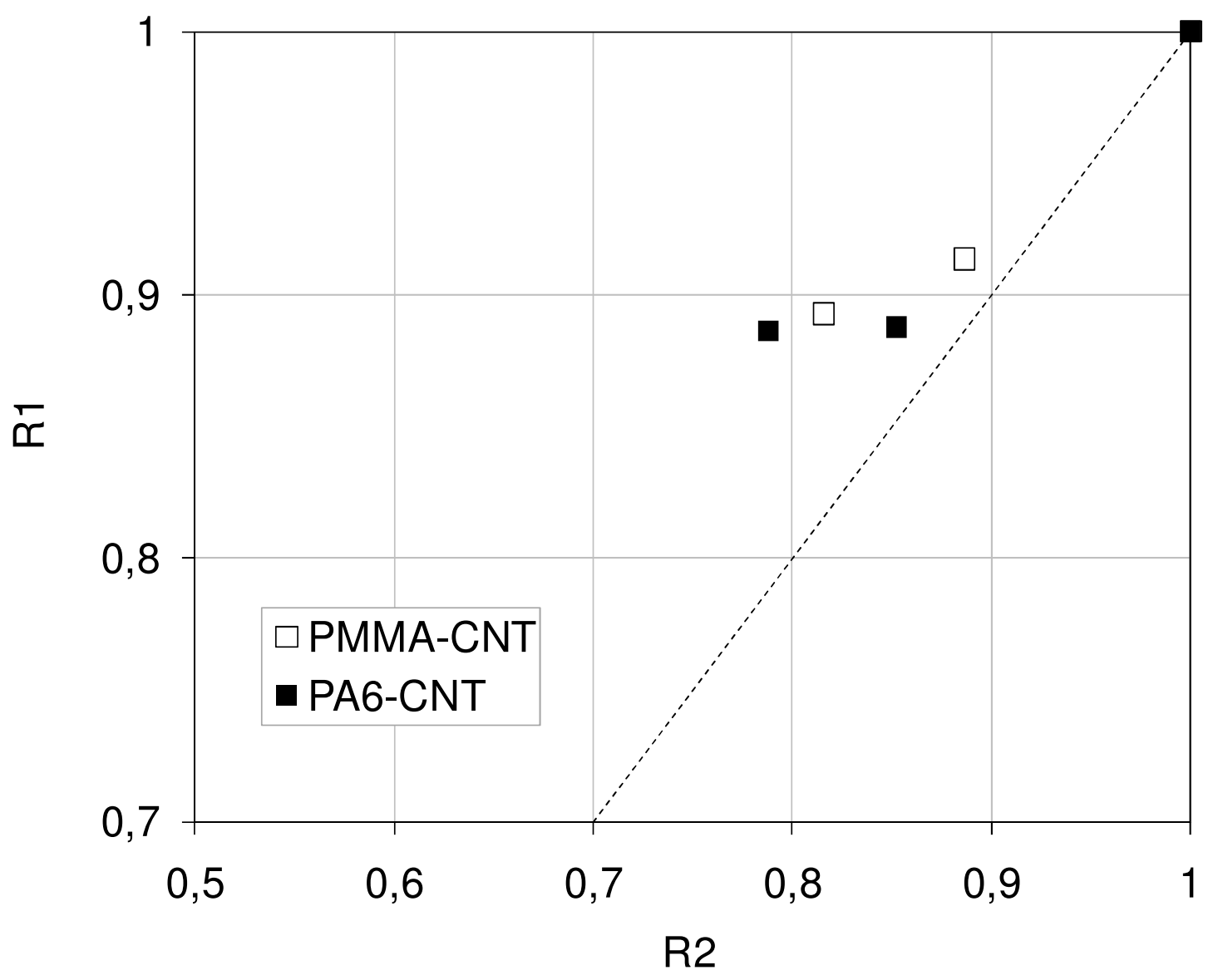


Figure 15 - STEM observations of PMMA-CNT (left) and PA6-CNT (right)
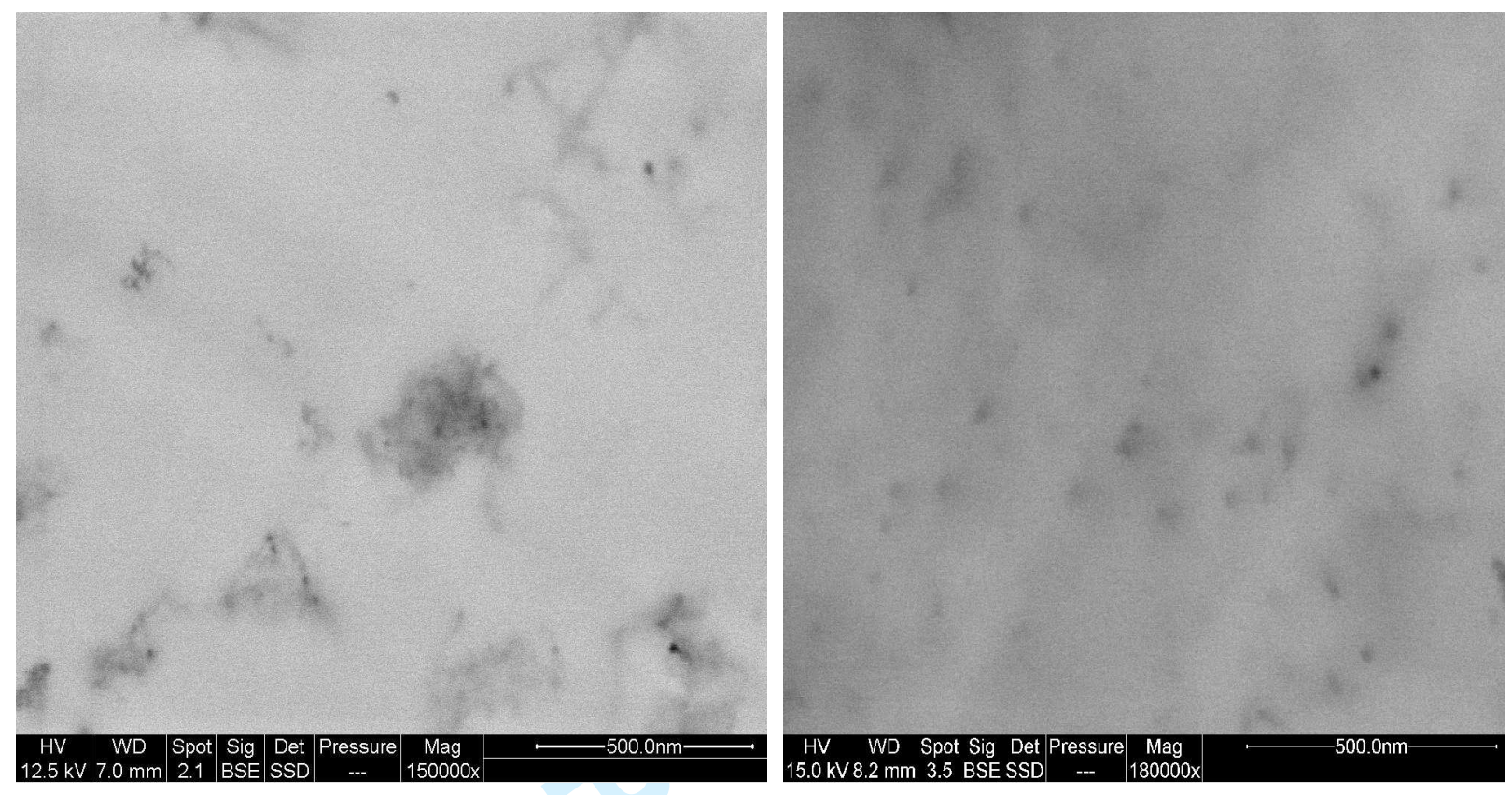
Figure 16 - Relative pHRR in PCFC versus CNT content for PMMA-CNT and PA6-CNT

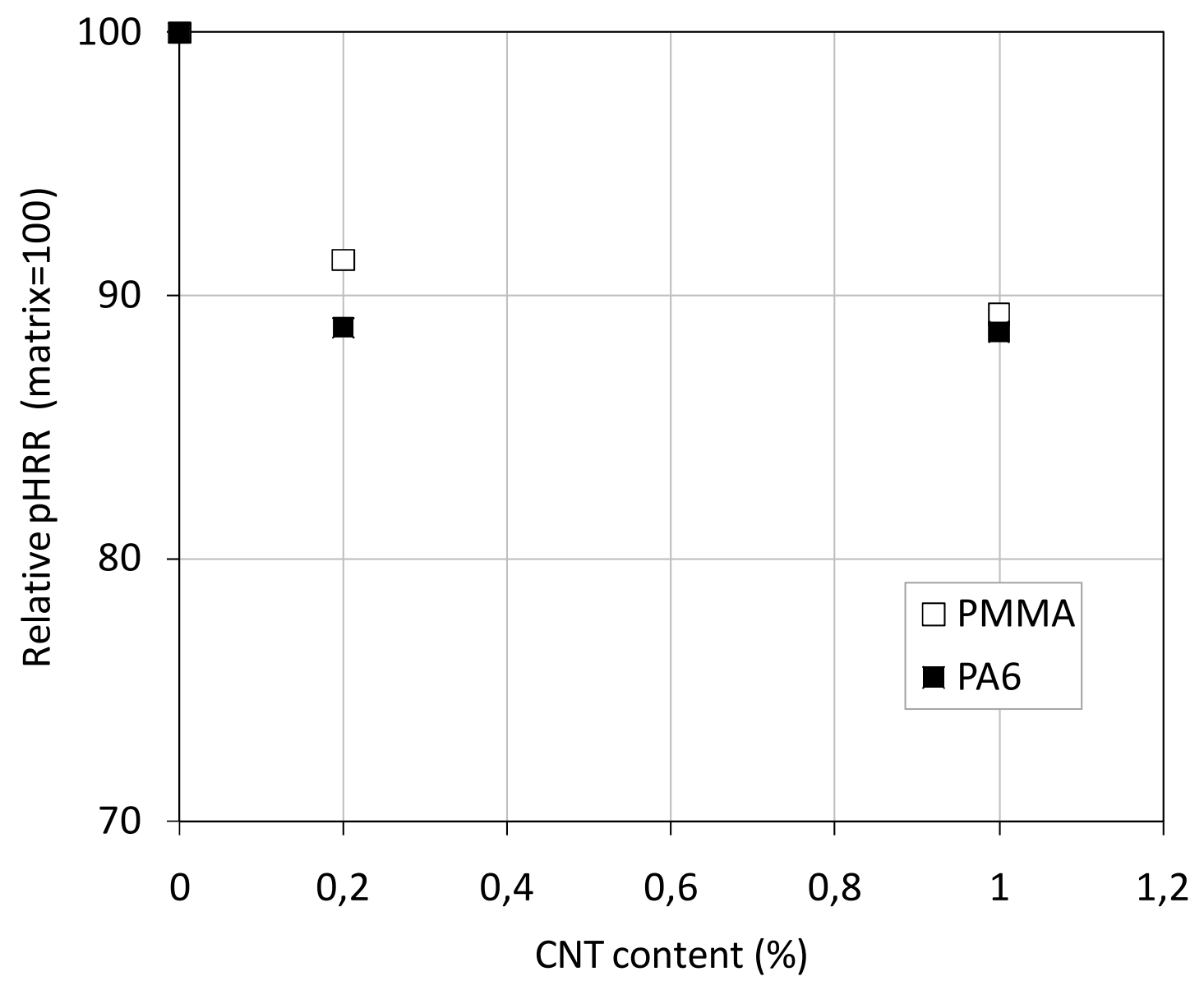

